\title{
An Overview of the GIS Weasel
}

\author{
By Roland J. Viger
}

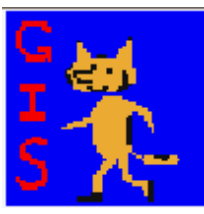

The GIS Weasel is a product of the Modeling of Watershed Systems (MoWS) project (http://wwwbrr. cr.usgs.gov/projects/SW_MoWS/), a part of the USGS National Research Program. This project seeks better understanding of hydrologic processes, their spatial and temporal variability, and their interactions across scales. These goals are met through the development of more robust computational models, as well as parameter estimation techniques.

This fact sheet provides a highlevel description of the GIS Weasel, a software system designed to aid users in preparing spatial information as input to lumped and distributed parameter environmental simulation models (ESMs). The GIS Weasel provides geographic information system (GIS) tools to help create maps of geographic features relevant to the application of a user's ESM and to generate parameters from those maps. The operation of the GIS Weasel does not require a user to be a GIS expert, only that a user has an understanding of the spatial information requirements of the model. The GIS Weasel software system provides a GISbased graphical user interface (GUI), $C$ programming language executables, and general utility scripts. The software will run on any computing platform where ArcInfo Workstation (version 8.1 or later) and the GRID extension are accessible. The user controls the GIS Weasel by interacting with menus, maps, and tables.

\section{Introduction}

The GIS Weasel is based on the ArcInfo Workstation GIS (ESRI, Inc., 2001). The only required input is a raster elevation data set, commonly referred to as a digital elevation model (DEM), stored in an ESRI GRID format. The GIS Weasel creates a variety of products, most notably digital spatial data sets and text parameter files. All interfaces to the GIS Weasel tools are menu and map driven. The user does not need to have any knowledge of the command line operating procedures of a GIS. The system has three major processing phases: setup, delineation, and parameterization.

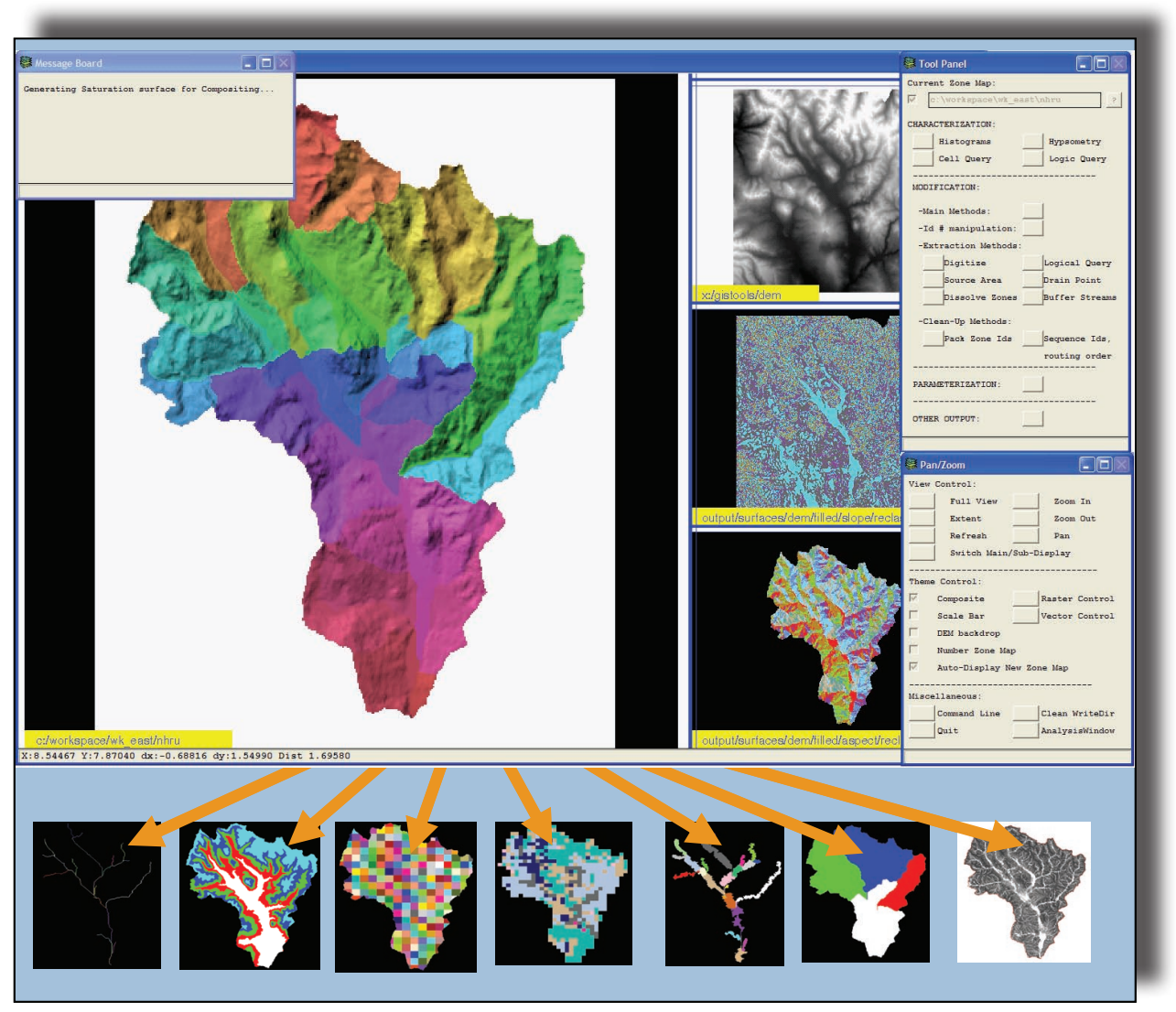

The GIS Weasel helps modelers develop maps of many kinds of geographic features.

\section{The Setup Phase}

In the setup phase, a variety of topographic surfaces are derived from the user-supplied DEM. The most important of these products are

1. a version of the DEM useful for routing hydrologic flow,

2. a surface of flow direction values,

3. a surface of flow accumulation values (measuring upstream contributing area), and

4. the area of interest (AOI).

The AOI represents the geographic extent of the modeling domain and serves to spatially limit almost subsequent outputs. The AOI is usually a watershed, although it can represent a groundwater system, an ecological unit, or any arbitrary land feature. The setup phase of a GIS Weasel processing session establishes many of the most commonly needed maps for delineating geographic features relevant to most ESMs. 


\section{The Delineation Phase}

Once the setup phase is completed, the GIS Weasel provides the Tool Panel to allow the user to delineate different kinds of geographic features within the AOI. Here, the GIS Weasel functions like a toolbox; the user is able to select and control tools to create maps of features needed for their ESM. The user is able to control which geographic data sets are used as input to each tool, and thus has the option of integrating previously derived data into an ongoing GIS Weasel processing session. When a tool requires user input, the interaction has been simplified and is clearly explained through contextual menus.

The GIS Weasel is a general toolset for the application of ESMs. This means the user is responsible for correctly applying a tool or sequence of tools. The GIS Weasel has no ESM-specific knowledge, and therefore it will not force the usage of a specific geoprocessing methodology.

There are several tools that have been developed in support of specific ESMs, such as the Precipitation Runoff Modeling System (PRMS) (Leavesley and others, 1983) and TOPMODEL (Beven and others, 1995) watershed models. "Plug-ins" are available for more comprehensive support of selected ESMs. Plug-ins range in content from ESM-specific instructions to whole sets of software that can be used in conjunction with the GIS Weasel. The development and use of plug-ins are documented in the GIS Weasel user's manual (Viger and Leavesley, 2007).

\section{The Parameterization Phase}

After the user has created maps of the different geographic features to be modeled, information can be generated about each map to create a set of ESM parameters. The GIS Weasel contains a library of over two hundred parameterization routines. The user can apply any of the routines to most raster maps, although the relevancy of the output from a routine for a particular ESM needs to be determined by the user. While the delineation phase of a GIS Weasel processing session is highly interactive, the parameterization phase is highly automated. Once the user specifies the list of parameterization methods and the maps to which the methods will be applied, almost no further user input is required. The GIS Weasel will produce "parameter maps" showing the derived information. These maps are then processed by the GIS Weasel to produce simple ASCII files containing all the requested parameter information. There

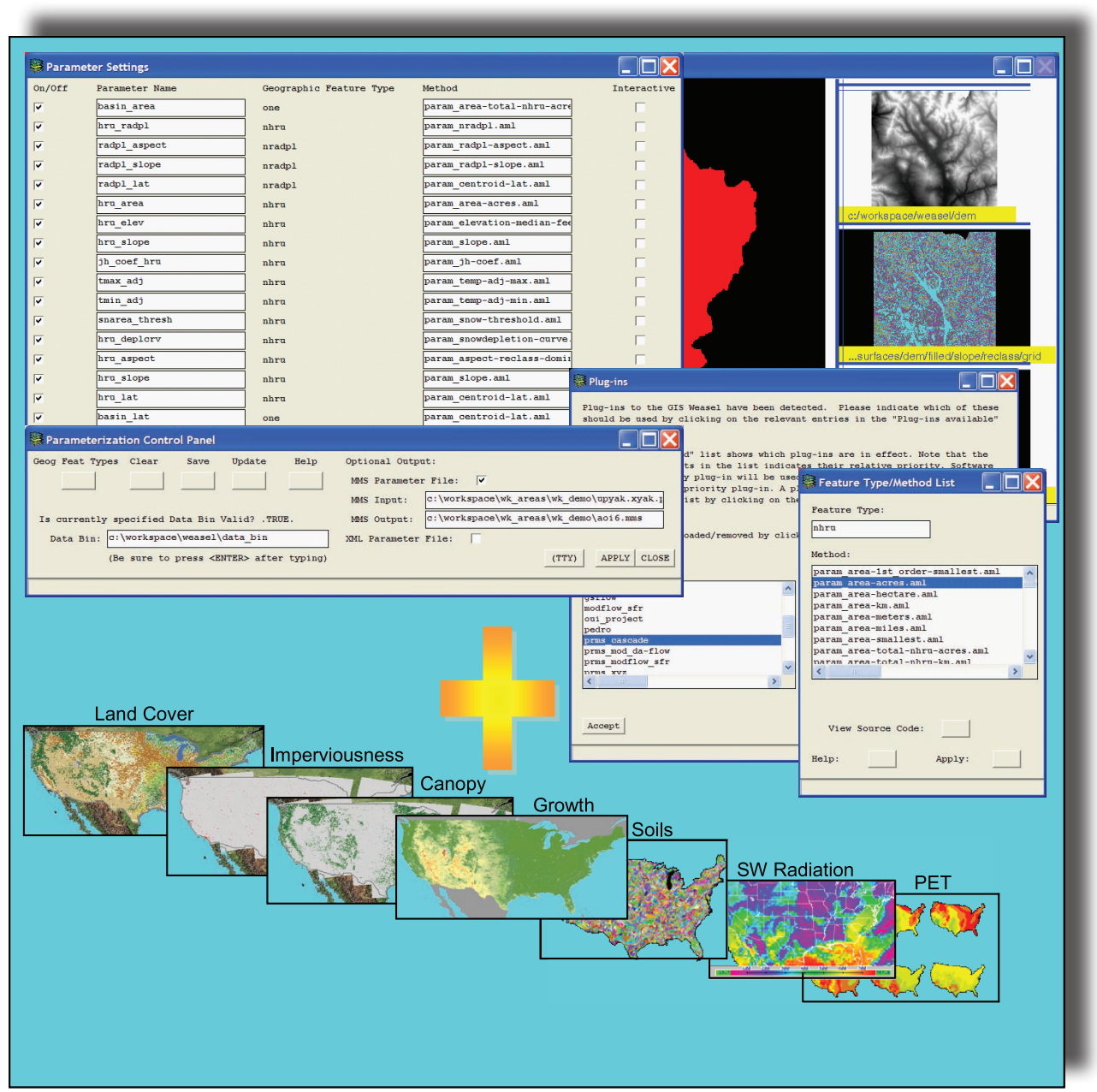

The GIS Weasel allows modelers to integrate different kinds of spatial data to generate many kinds of parameters.

is an option in this process to produce an additional file that is specifically formatted for use with the Modular Modeling System (Leavesley and others, 1996; http://wwwbrr. cr.usgs.gov/mms). Even if these formats are incompatible with the ESM, the ASCII files have been designed for easy reformatting by external tools such as Microsoft Excel, Microsoft Access, Python, AWK, or Perl.

\section{Availability}

The GIS Weasel is available from the web page http://wwwbrr.cr.usgs.gov/ weasel, along with a user's manual, online training, email support, and other resources.

\section{References Cited}

Beven, K.J., Quinn, P.F., Romanowicz, R.J., Freer, J., Fisher, J.I., and Lamb, R., 1995, TOPMODEL and GRIDATB-A user's guide to the distribution versions (95.02): Lancaster, United Kingdom, Lancaster University, Institute of Environmental and Biological Sciences, Centre for Research on Environmental Systems and Statistics, 31 p.
ESRI, Inc., 2001, ArcInfo Workstation, Version 8.1 [software].

Leavesley, G.H., Lichty, R.W., Troutman, B.M., and Saindon, L.G., 1983, Precipitation-runoff modeling system-User's manual: U.S. Geological Survey WaterResources Investigations 83-4238, 207 p.

Leavesley, G.H., Restrepo, P.J., Markstrom, S.L., Dixon, M., and Stannard, L.G., 1996, The modular modeling system (MMS)_User's manual (ver. 1.1): U.S. Geological Survey Open-File Report 96-151, $142 \mathrm{p}$.

Viger, R.J., and Leavesley, G.H., 2007, The GIS Weasel user's manual: U.S. Geological Survey Techniques and Methods, book 6, chap. B4, 201 p., http://pubs. usgs.gov/tm/2007/06B04/.

\section{Contact Information}

Modeling of Watershed Systems Project U.S. Geological Survey

MS 412, Box 25046 Denver Federal Center Denver, CO 80225

MoWS_help@usgs.gov 